\title{
Retained intrauterine devices in pregnancy
}

\author{
Ari P. Sanders MD, Barry H. Sanders MD
}

Cite as: CMAJ 2018 April 9;190:E440. doi: 10.1503/cmaj.171059

1

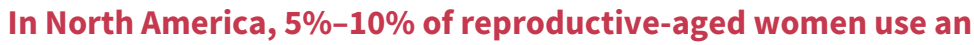
intrauterine device for contraception ${ }^{1}$

With typical use, unintended pregnancy rates in the first year after insertion are $0.8 \%$ for the copper-containing intrauterine device (IUD) and $0.2 \%$ for the levonorgestrel-releasing intrauterine system. ${ }^{2}$

\section{Pregnancies are at increased risk of adverse outcomes with a retained IUD}

A systematic review in 2012 found increased rates of spontaneous abortion $(48 \%-77 \%)$ and preterm delivery $(7 \%-25 \%)$ with a retained IUD. Other risks included preterm premature rupture of membranes, chorioamnionitis, septic abortion and placental abruption. ${ }^{3}$ It is unclear whether the risk of congenital anomalies is increased with a retained IUD. ${ }^{3}$

\section{3}

\section{Current evidence supports removal of retained IUDs in} pregnancy

Prospective and retrospective cohort studies identified in the 2012 systematic review show significant improvements in pregnancy outcomes after removing an IUD in early pregnancy versus leaving it in place. ${ }^{3}$ Of those cohort studies, the best-quality evidence showed reductions in spontaneous abortion rates from $54 \%$ to $20 \%$, and reductions in preterm delivery rates from $17 \%-18 \%$ to $4 \%-14 \%$, but not to baseline rates. ${ }^{3}$

There are procedures to remove intrauterine devices in pregnancy when the strings are not visible

Case series have identified hysteroscopic retrieval ${ }^{4}$ and ultrasound-guided retrieval ${ }^{5}$ as safe and effective methods for removal of IUDs in pregnancy when the strings are not present or retrievable on examination. The complication rates of these procedures are reported to be low, and improvements in pregnancy outcomes are comparable with those after IUDs with visible strings have been removed. ${ }^{4,5}$

When pregnancy continuation is desired, retained IUDs should be removed at the earliest gestational age possible ${ }^{3-5}$

After confirmation of pregnancy, we suggest an ultrasound to confirm viability, rule out ectopic pregnancy and document location of the IUD. If the IUD strings are visible on examination, the primary care provider is encouraged to remove the IUD after obtaining patient consent. For lost IUDs in pregnancy, we suggest giving the patient an urgent outpatient referral to a gynecologist experienced in advanced hysteroscopy, or to a maternal-fetal medicine specialist with sonographic expertise, for consideration of IUD removal.

\section{References}

1. Black A, Guilbert E, Costescu D, et al. Canadian contraception consensus (part 3 of 4): Chapter 7 - intrauterine contraception. J Obstet Gynaecol Can 2016;38:182-222.

2. Trussell J. Contraceptive failure in the United States. Contraception 2011;83:397-404.

3. Brahmi D, Steenland MW, Renner RM, et al. Pregnancy outcomes with an IUD in situ: a systematic review. Contraception 2012;85:131-9.

4. Sanders AP, Fluker MR, Sanders BH. Saline hysteroscopy for removal of retained intrauterine contraceptive devices in early pregnancy. J Obstet Gynaecol Can 2016;38:1114-9.

5. Schiesser M, Lapaire O, Tercanli S, et al. Lost intrauterine devices during pregnancy: maternal and fetal outcome after ultrasoundguided extraction. An analysis of 82 cases. Ultrasound Obstet Gynecol 2004;23:486-9.

\section{Competing interests: None declared.}

This article has been peer reviewed.

Affiliations: Department of Obstetrics and Gynecology (A. Sanders), University of Toronto, Mount Sinai Hospital, Toronto Ont.; Department of Obstetrics and Gynecology (B. Sanders), University of British Columbia, BC Women's Hospital \& Health Centre, Vancouver, BC

Correspondence to: Ari Sanders, arisanders@hotmail.com

CMAJ invites submissions to "Five things to know about ..." Submit manuscripts online at http://mc. manuscriptcentral.com/cmaj 